\title{
LA LIQUIDACIÓN DE LA REFORMA TÉCNICA DE LA AGRICULTURA. ALGUNOS ESTUDIOS DE CASO EN LOS POBLADOS DE COLONIZACIÓN DE LA PROVINCIA DE JAÉN
}

\author{
Eduardo Araque Jiménez \\ Área de Análisis Geográfico Regional \\ Universidad de Jaén
}

\section{RESUMEN}

Este trabajo trata de poner de relieve el fracaso de la reforma técnica de la agricultura emprendida en España a partir de 1939. Se ha elegido para comprobarlo la provincia Jaén, donde los dos principios sobre los que se sostenía aquella reforma (transformación en regadío y reparto de pequeños lotes de tierras agrícolas) alcanzaron mayores dimensiones. Hemos optado por seleccionar cinco estudios de caso, correspondientes a otros tantos poblados de colonización, para analizar la evolución del terrazgo agrícola desde mediados del siglo xx hasta la actualidad. Mediante el uso combinado de la fotografía aérea y el trabajo de campo, se ha podido comprobar que lejos de una intensificación y diversificación de la agricultura, como proponía la reforma técnica, se ha avanzado hacia un régimen de monocultivo del olivar que no difiere del que se ha impuesto en el resto de la provincia de Jaén. La influencia de la Política Agraria Común, a través del establecimiento de un generoso sistema de ayudas al aceite, ha resultado decisiva también en la consagración del terrazgo a este único cultivo.

Palabras clave: Jaén, colonización, regadío, política agraria, olivar, monocultivo

\section{ABSTRACT}

The end of the technical reform of agriculture. Some case studies in the colonization villages in the province of Jaén.

This work emphasizes the failure of the technical reform of agriculture undertaken in Spain since 1939. To check it the province of Jaén has been elected, where the two principles that support that reform (irrigation and distribution of small lots of rural land) achieved the largest dimensions. We have chosen to select five case studies, 
corresponding to several colonization villages, to analyze the evolution of the agricultural surface since the middle of xxth Century until nowadays. With the combined use of aerial photography and field work, it has been able to check that an agricultural intensification and diversification have not been realized, like the technical reform proposed, the other way round, the monoculture of olive grove has grown, which it is not different to the evolution in the rest of the province of Jaén. The influence of Common Agricultural Policy, that has established a generous system of grants for the olive oil, has turned on decisive to dedicate the land only to the olive grove.

Keywords: Jaén, colonization, irrigation, agricultural policy, olive grove, monoculture.

\section{INTRODUCCIÓN}

La política agraria que empezó a articular el régimen de Franco nada más constituirse el denominado gobierno de Burgos, tenía entre sus principales objetivos la transformación en regadío de las amplias vegas de los principales ríos españoles. Lo dejó meridianamente claro en un preámbulo que no tiene ningún desperdicio, la primera ley agraria promulgada tras constituirse formalmente el primer gobierno del «nuevo Estado»: la ley de colonización de grandes zonas. Usando y abusando de una retórica genuinamente falangista, declaraba el riego como «la transformación más revolucionaria que pueda hacerse en el suelo», para añadir, acto seguido, que «el clamor de los combatientes y del pueblo y la sangre derramada por los ideales de la nueva revolución exigen no sólo la superación (separación en el texto legal) de los obstáculos que a ello se opongan, sino la colaboración de los diferentes intereses para llevar a cabo, con ritmo acelerado, la colonización de grandes zonas regables».

Más allá de esa palabrería rimbombante, en el contexto político y socioeconómico en el que se desenvolvió el régimen de Franco durante su primera década, la transformación en regadío a gran escala resultaba transcendental, sencillamente, por razones de estricta supervivencia de la población, aunque tal extremo no llegara nunca a reconocerse abiertamente por los dirigentes políticos. Sin posibilidad de acudir a los mercados exteriores a proveerse de los recursos indispensables para la correcta alimentación de la población, por el aislamiento al que estaba sometida España, no quedaba más alternativa que la intensificación de la agricultura para conseguir un incremento de la producción nacional de alimentos, que fuera capaz de hacer frente a la permanente amenaza del hambre, la máxima preocupación de todas las autoridades e instituciones públicas del momento por su temible derivación en un estallido social de impredecibles consecuencias (Arias, 1951; Araque, 1983; Gallego, 2012).

En Andalucía, y de un modo muy especial en la provincia de Jaén -donde la hambruna de 1946 había causado verdaderos estragos-, la transformación en 
regadío resultaba, si cabe, más perentoria que en la mayor parte del resto del territorio regional. Se contaba para ello con una excepcional fuente de abastecimiento de agua como era el pantano del Tranco, inaugurado en 1948, y con unas amplias y feraces terrazas modeladas por el Guadalquivir en las que la introducción del regadío resultaba relativamente fácil y no excesivamente gravosa. Además de un incremento de la producción, del riego de los campos se esperaba el surgimiento de una nueva agricultura mucho más diversificada que la tradicional -basada casi exclusivamente en el cereal y el olivar-, que contribuyera a erradicar la tremenda lacra del paro crónico que padecía la inmensa mayoría de la población activa agraria, y ayudara a fundamentar una potente industria de transformación: la gran asignatura histórica pendiente de superar en la provincia. Todo lo anterior se completaba con una redistribución muy limitada de la propiedad de la tierra y el asentamiento de un nutrido grupo colonos en los distintos poblados construidos en las grandes zonas regables, siguiendo para ello los criterios que en cada caso estableciera el Instituto Nacional de Colonización (INC). En esencia estas eran las grandes líneas de actuación de la nueva reforma técnica de la agricultura que auspició el franquismo en tierras jiennenses; una reforma que, como afirmaba Bosque Maurel en una valoración de conjunto (1984), se mostraba ajena a cualquier transformación generalizada de la estructura de la propiedad de la tierra y se dirigía exclusivamente a una mejora generalizada de la productividad y a una maximización de la producción y el consumo.

Tratar de mostrar hasta qué punto se han alcanzado esos objetivos en lo que atañe a la introducción y permanencia de nuevos cultivos alternativos a los tradicionales, es el fin primordial que persigue este trabajo. Puesto que no podemos abordar el estudio de la totalidad de las zonas regables -ya que ello desbordaría ampliamente los límites fijados por los editores-, hemos optado por seleccionar una serie de núcleos de colonización para observar en cada caso la secuencia cronológica de los cambios experimentados en la fracción del terrazgo que se asignó a los colonos, así como las causas que los impulsaron.

Se ha elegido para ello un núcleo de colonización de cada una de las cinco grandes zonas regables que se conformaron en el entorno del Guadalquivir y de sus afluentes Guadalimar y Guadalen. En cuatro de esos núcleos, la tierra se distribuyó en lotes familiares y complementarios - de 5 ha y 0,5 ha de extensión, respectivamente- en diferente proporción, mientras que en el quinto, como en toda la zona alta del Guadalquivir en la que está enclavado el poblado de Solana de Torralba, sólo se repartieron esta última clase de lotes (Cuadro 1). Por esa razón, en esta zona, hemos decidido elegir aquel núcleo en el que se asentó un mayor número de colonos y se repartió más superficie de tierra. Así mismo hemos procurado seleccionar núcleos de diferente tamaño en cuanto al número 
total de lotes repartidos, a fin de comprobar si existen diferencias significativas en razón de esa variable superficial.

Cuadro 1. Distribución de lotes en los núcleos de colonización seleccionados

\begin{tabular}{|l|l|r|r|}
\hline \multicolumn{1}{|c|}{ Zona } & \multicolumn{1}{c|}{ Núcleo } & $\begin{array}{c}\text { Lote } \\
\text { Familiar }\end{array}$ & $\begin{array}{c}\text { Lote } \\
\text { complementario }\end{array}$ \\
\hline Alta del G. & Solana de Torralba & 155 & 196 \\
\hline Media del G. & Campillo del Rio & 10 & 61 \\
\hline Baja del G. & Ampliación de Espelúy & 57 & 14 \\
\hline Rumblar & La Quintería & 61 & 20 \\
\hline Guadalen & Guadalen & & 16 \\
\hline
\end{tabular}

Fuente: Araque (1983). Citado en bibliografía.

El trabajo se apoya en distintas ortofotos que forman parte de la fototeca aérea del Instituto de Estadística y Cartografía de Andalucía, así como en el parcelario obtenido en la oficina virtual del Catastro, fundamentales ambas para abordar un estudio diacrónico sobre los paisajes agrarios. Pero no se limita a esa base cartográfica, que en estudios de detalle sobre evolución de cultivos presentan algunas lagunas de interpretación. Se ha recurrido también a otras fuentes estadísticas $\mathrm{y}$, sobre todo, a un minucioso trabajo de campo en cada uno de los poblados seleccionados, para tratar de precisar determinados aspectos que no es posible reconocer mediante las fotografías aéreas, y, desde luego, para superar la fase descriptiva a la que aboca esa fuente cuando no se utilizan otros medios de información complementarios.

\section{COLONIZACIÓN DE LAS GRANDES ZONAS REGABLES}

Como hemos expuesto en distintas ocasiones, el grueso de las obras de transformación en regadío que se llevaron a cabo durante la posguerra en la provincia de Jaén, se circunscribió a las cinco grandes zonas regables de interés nacional que se declararon oficialmente entre 1948 y 1951. No obstante, su ejecución recibió un impulso definitivo a partir del momento en que se aprobó el Plan Jaén en 1953, que fue el que realmente dispuso de los medios necesarios para abordar esa tarea. En todas ellas la introducción del regadío se acompañó de la instalación de nuevos colonos en la veintena de poblados que se construyeron al efecto, a cada uno de los cuales se dotó de un lote de tierra, así como de una vivienda y otros elementos y enseres necesarios para abordar la explotación en las mejores condiciones posibles en esos momentos. La originalidad de la provincia de Jaén en el contexto nacional y regional radicó en la forma tan peculiar de reparto de las calificadas como tierras en exceso -destinadas a su distribución 
entre colonos -que se delimitaron en cada una de las grandes zonas regables, ya que aquí se apostó abiertamente por la asignación de lotes complementarios en detrimento de los más extensos lotes familiares, llegando a darse el caso, como se ha avanzado, de que en una de esas zonas -la Alta del Guadalquivir-, no se distribuyó ni un solo lote familiar de los más de 700 que se asignaron a los colonos instalados. En las restantes zonas, como se muestra en el CUADRO, la proporción de unos y otros lotes resultó muy variable, pero en conjunto, como decimos, a 3 de cada 4 colonos instalados se les asignó un diminuto huerto familiar.

Cuadro 2. Distribución absoluta y relativa de los lotes entregados a colonos

\begin{tabular}{|c|c|c|c|c|}
\hline \multirow[t]{2}{*}{ Zona regable } & \multicolumn{2}{|c|}{ Lote familiar } & \multicolumn{2}{|c|}{ Lote complementario } \\
\hline & N. ${ }^{\circ}$ & $\%$ & $\mathrm{~N}^{\mathrm{o}}$ & $\%$ \\
\hline Alta Guadalquivir & - & - & 706 & 100 \\
\hline Media Guadalquivir & 155 & 22,3 & 540 & 77,7 \\
\hline Baja Guadalquivir & 78 & 31,2 & 172 & 68,8 \\
\hline Rumblar & 153 & 91,6 & 16 & 8,4 \\
\hline Guadalen & 61 & 75,3 & 20 & 24,7 \\
\hline Total & 447 & 23,5 & 1.454 & 76,5 \\
\hline
\end{tabular}

Fuente: Araque (1983). Citado en bibliografía

La obligación política de instalar a un elevado contingente de colonos en las zonas regables -en una provincia con abundante presencia histórica de pequeños campesinos y jornaleros sin tierra, donde los ecos de la reforma agraria republicana no se habían apagado del todo-y dotar a todos ellos de una superficie mínima, imprescindible para atender sus estrictas necesidades de subsistencia, actuó a favor de este sistema de reparto de las exiguas tierras en exceso que se delimitaron en cada zona regable. Era la mejor forma de reforzar a los medianos y grandes propietarios a los que se habían reservado sus tierras en los proyectos generales de colonización de cada gran zona. En unos momentos de emigración generalizada en el medio rural jiennense, sólo manteniendo junto a esas explotaciones a una masa considerable de pequeños campesinos, podía cubrirse el incremento de la demanda de mano de obra, que era previsible que secundara a la introducción del regadío.

Tras la instalación de los colonos, durante los primeros años de estancia en los poblados, la agricultura estuvo dirigida por el cuerpo técnico del INC, que determinó en cada caso el tipo y los métodos de cultivo más apropiados, de acuerdo con las características agronómicas de las grandes zonas regables. Apenas se dejó libertad a los agricultores a la hora de elegir los cultivos -al 
margen de aquellos que se plantaban en los pequeños huertos que cada colono destinaba al abastecimiento familiar-, aun a sabiendas de que la inmensa mayoría de ellos no conocían en absoluto las nuevas plantas y no estaban entrenados, por tanto, en su manejo.

En consonancia con esos planteamientos, en un primer momento quedaron expresamente excluidos de las tierras regables los cereales y el olivar, no tanto porque se considerara inapropiado su cultivo en regadío, como porque ninguno de ellos demandaba un volumen de mano de obra capaz de reducir mínimamente las elevadas tasas de paro agrario que padecía la población rural jiennense. También, y eso no puede perderse de vista, porque ambos ya estaban suficientemente extendidos en el resto de las tierras labrantías provinciales. De hecho, en uno de los poblados estudiados, La Quintería, se procedió al arranque masivo de los viejos pies de olivo antes de que dieran comienzo las obras de transformación en regadío previstas por el INC. Las fotografías aéreas y convencionales que se han conservado de esos momentos, así como la documentación que se custodia en distintos archivos, atestiguan perfectamente este curioso fenómeno de erradicación del olivar.

En lugar de esos cultivos tradicionales se apostó por otros mucho más exigentes en mano de obra, pero que apenas eran conocidos en la provincia, o que si se habían cultivado con anterioridad era a una escala tan reducida como la que forzosamente imponía el autoconsumo familiar o la alimentación de la ganadería doméstica. Así sucedía, por citar algunos ejemplos, con el tabaco o con el maíz, o más ampliamente con los frutales y los variados cultivos hortícolas. Ahora se apostaba por un cambio en la escala productiva, para lo cual se requería inexcusablemente la adopción de un plan de formación previo dirigido a los agricultores, que los capacitara para afrontar los retos técnicos y agronómicos que exigían las nuevas plantaciones, en algunos casos de variedades completamente desconocidas en el agro jiennense. Esa vertiente de la reforma se descuidó en extremo, tanto por parte del INC, como por el resto de administraciones con competencias en la materia, mucho más preocupadas por la implantación de «escuelas aceleradas» de formación de trabajadores en los distintos ramos de la industria, dispuestos a engrosar de inmediato la desbocada corriente migratoria jiennense.

La propuesta de distribución de cultivos que impuso el INC, no sólo tenía la ventaja de ser más provechosa desde el punto de vista de la generación de empleo, sino que abría la puerta a la transformación industrial de la mayor parte de ellos y, en definitiva, a la recuperación por parte de los agricultores jiennenses de una parte muy importante del valor añadido bruto que generaban esos recursos. Para alcanzar ese objetivo tan ansiado, el Plan Jaén y el patronato pro industrialización que surgió a su amparo, contemplaban la creación de múltiples industrias de transformación agraria con capacidad para procesar la totalidad 
de los recursos obtenidos en las zonas regables e incluso los restos vegetales de los mismos, en un intento pionero de aprovechamiento integral de la riqueza agraria. Algunas de estas industrias de manipulación y envasado de productos hortofrutícolas e industriales, se crearon y estuvieron funcionando algunos años con un notable éxito comercial que evidenciaba su importante cuota de mercado. Durante ese lapso de tiempo se pudo evidenciar el acierto de quienes habían apostado por la reforma técnica de la agricultura frente al modelo republicano de redistribución de la propiedad de la tierra. Las grandes zonas regables se convirtieron así en un diminuto pero auténtico oasis de diversidad agrícola frente a los extensos campos de secano que las envolvían, dominadas por los seculares monocultivos olivarero y cerealista, aunque con la presencia tímida, ya en los años setenta, de algunas plantas industriales como el girasol o el algodón.

Sin embargo, el ambicioso programa agroindustrial que contemplaba el Plan Jaén muy pronto devino en una empresa irrealizable. Muchas de las industrias previstas ni siquiera llegaron a proyectarse porque jamás se implantaron los cultivos de los que debían abastecerse; otras, después de que los empresarios interesados estudiaran minuciosamente su viabilidad, se desestimaron por una evidente falta de rentabilidad; incluso algunas de las que estuvieron funcionando durante unos años con evidente éxito comercial, de la noche a la mañana cerraron sus instalaciones. Podríamos exponer numerosos ejemplos de cada una de ellas, pero baste con señalar el de la empresa Sacove, una industria modélica en la elaboración de concentrado de tomate y fabricación de mermeladas, pionera en la exportación de parte de su producción a Europa, y con una envidiable solvencia económica, que poco después de empezar a producir clausuró su planta de Mengíbar sin aparentes razones para ello o, al menos, sin que se hicieran públicas las causas que habían abocado a esa situación (Araque, 2014). En suma, a mediados de los años setenta, momento en que dejó de estar vigente el Plan Jaén, casi toda la estrategia de industrialización agraria se había convertido en un completo fiasco del que sólo se salvaban algunas pequeñas fábricas aisladas con una débil capacidad productiva, incapaces de sobrevivir en un mercado ampliado.

La cicatería del INC a la hora de proceder al reparto de la tierra -justificada por el interés no explicitado del régimen en sostener y reforzar el latifundismo agrario-, unido a la falta de cualificación de la gran mayoría de los colonos para el mantenimiento de unos cultivos que desconocían por completo -ni conocían los ciclos biológicos de las plantas ni las técnicas de riego ni las dosis de aguay a la incapacidad manifiesta de un empresariado dispuesto a asumir los retos que planteaba el proceso de industrialización agraria, dieron al traste con la estrategia de desarrollo que se había planteado en las grandes zonas regables de la provincia. La muestra más elocuente de ese fracaso fue el abandono en masa de los nuevos cultivos implantados a partir del momento en que los llamados a 
practicarlos se vieron liberados de la obligación de plantarlos. Se inició así un proceso de desmoronamiento de los cimientos sobre los que se había levantado la reforma técnica de la agricultura en la provincia de Jaén, que no fue simultáneo en todas las zonas regables ni en todos los poblados de colonización, pero que al cabo de los años condujo o está conduciendo a idéntica situación.

\section{LOS ÚLTIMOS COLETAZOS DE LA REFORMA TÉCNICA}

De acuerdo con las primeras ortofotos analizadas, realizadas entre 1977 y 1980 , y con la información obtenida en el trabajo de campo, el predominio de los cultivos herbáceos era muy nítido todavía en esos momentos del último cuarto del siglo xx. Entre todos ellos sobresalía el algodón, al que el gobierno, después de la fuerte retracción superficial que había experimentado el cultivo desde el inicio de los años sesenta -momento en que la superficie algodonera alcanzó su cenit-, trató de estimular mediante subvenciones para la compra de los insumos necesarios para la producción (Sumpsi, 1980), y a través de un sustancial incremento del precio de la fibra, que casi llegó a duplicarse entre 1962 y 1974 (Velasco, 1976). En aras a la ampliación de superficie, en abril de 1979 entro en vigor el Plan indicativo para la expansión del cultivo algodonero, que aspiraba a incrementar la producción de fibra de calidad en las zonas de regadío -se desechaba definitivamente el cultivo en secano por sus bajos rendimientos-, con el fin de frenar a través de este cultivo calificado como social la ostensible pérdida de jornales que estaba teniendo lugar en el campo español (Rodríguez y Ruiz, 1996). Para lograrlo era imprescindible reducir los costes de producción mediante la mecanización de la recolección, lo cual no resultaba incompatible con la función social de esta planta, dado que el plan perseguía la eliminación de otros cultivos menos exigentes en mano de obra y su sustitución por el algodón, que aun mecanizado, seguía proporcionando un buen número de jornales en determinadas labores que obligatoriamente había que seguir realizando de modo manual: colocación de plástico tras la siembra, escarda, etc.

En las grandes zonas regables jiennenses podía atenderse perfectamente a esta demanda expansiva sin demasiado gasto público en ayudas a la modernización del sistema regadío, puesto que las estaciones elevadoras de agua y las redes de distribución eran de reciente construcción y ambas estaban perfectamente capacitadas para dar cumplida respuesta a las elevadas exigencias hídricas de esta planta, muy variables según el sistema de riego empleado, pero en todo caso abultadas ${ }^{1}$. Así mismo, por su suave topografía - una de las operaciones de mayor calado que se llevaron a cabo en las tierras en exceso antes de la puesta en

1. Las dotaciones óptimas fluctuaban entre $\operatorname{los} 6.000-7.000 \mathrm{~m}^{3} / \mathrm{ha}$ en un sistema de riego por gravedad -dominante en las zonas regables jiennenses-y los $5.000-5.500 \mathrm{~m}^{3} / \mathrm{ha}$ del riego por aspersión o los $4.000-4.500 \mathrm{~m}^{3} / \mathrm{ha}$ del riego por goteo (DAP, 2002). 
riego, consistió en la nivelación de suelos-no se planteaban demasiadas dificultades a la hora de abordar el proceso de mecanización de la recolección. Por otro lado en dos localidades situadas estratégicamente dentro del área de influencia de las zonas regables, Baeza y Mengíbar, se habían constituido a principios de los años sesenta sendas desmotadoras - una de propiedad privada y la otra en régimen cooperativo-, a las cuales los agricultores podían entregar el algodón sin grandes dificultades ni excesivos costes de transporte.

A este tipo de pequeñas industrias de transformación se encontraban vinculados otros cultivos como las plantas forrajeras -maíz y alfalfa, fundamentalmente - o la remolacha, que también estaban presentes en esos momentos en los poblados estudiados. En el primer caso, a la presencia de una fábrica de elaboración de piensos situada en la zona media del Guadalquivir, que había surgido bajo los auspicios del programa de industrialización del Plan Jaén y, cosa rara, había logrado consolidarse con los años a pesar de su escasa capacidad de producción. La remolacha, por su parte, se reintrodujo en los regadíos jiennenses después de haber estado ausente de ellos durante muchos años, a raíz de la implantación en 1973 de una planta azucarera en las inmediaciones de Linares. Era ésta otra de las industrias que había contemplado el patronato de industrialización del Plan Jaén, pero por diversas circunstancias no pudo abrirse hasta dos décadas después en un emplazamiento completamente distinto al inicialmente previsto ${ }^{2}$.

En estas fechas habían desaparecido del terrazgo casi por completo los cultivos hortofrutícolas. El cierre ya comentado de Sacove, en un primer momento, $\mathrm{y}$, posteriormente, el de otras industrias conserveras que abrieron sus puertas en distintas localidades de la provincia muy alejadas de las zonas de producción, como Linares o Siles, cercenaron cualquier posibilidad de transformación de los mismos y, en suma, de dar una salida rentable a los elevados niveles de producción de las vegas jiennenses. La otra alternativa de comercializar en fresco las frutas y hortalizas, resultaba una tarea casi utópica, debido a la fuerte competencia de los productos procedentes de los enarenados granadinos y almerienses, hegemónicos en el mercado por sus elevados niveles de producción durante todo el año, gracias a unas condiciones ambientales excepcionales (Morales, 2003). Los únicos vestigios de esa agricultura en la que tantas esperanzas se habían depositado, eran los pequeños huertos que muchos colonos cultivaban en ínfimas porciones de sus parcelas, cuyos frutos destinaban exclusivamente al autoabastecimiento de la unidad familiar.

2. La elección final del emplazamiento de la planta azucarera tuvo que ver con la oportunidad que suponía contar con las instalaciones de una industria de transformación de residuos agrícolas completamente terminada, que por un notorio error de planificación nunca llegó a abrir sus puertas. Sobre el particular puede verse Martín (1996). 
Aunque ya eran visibles algunas plantaciones de olivar, sobre todo en los lotes complementarios, la crisis que azotaba a este cultivo en esos momentos (López, 1980; Tió, 1982), suponía un riesgo muy elevado que impedía un cambio de cultivo tan drástico. No olvidemos que el olivo es un árbol que entra en producción, por término medio, a los diez años de ser plantado y, por tanto, durante ese período de tiempo el agricultor dejaba de obtener lucro alguno de la explotación de la tierra. Si además de ese hándicap tenemos en cuenta que las perspectivas de evolución futura de los precios del aceite eran muy poco halagüeñas -la presencia de otros aceites vegetales en el mercado nacional constituía una dura competencia para el aceite de oliva, muy desprestigiado como alimento saludable-, no debe extrañarnos que los agricultores prestaran tan poca atención al olivar. Pero quede claro que ya no existía ningún tipo de cortapisa que frenara su expansión en las zonas regables. De hecho, los redactores del Inventario agronómico del olivar elaborado a mediados de los años setenta (Dirección General de la Producción Agraria, 1975), únicamente había propuesto el arranque de un millar y medio de hectáreas plantadas en esas zonas en toda la provincia, por entender que eran más apropiados otro tipo de cultivos alternativos con mayores posibilidades económicas. Sin embargo, a ninguno de ellos se le escapaba que semejante pretensión era, en expresión popular, un verdadero brindis al sol. Desde un tiempo antes, en el marco de la policía de reconversión y reestructuración productiva del olivar que se había planteado en 1972, se venía primando la eliminación de árboles de las zonas regables. Pues bien, en el periodo 1972-1979 no se recibió ni una sola solicitud para ello en toda la provincia de Jaén (Dirección General de la Producción Agraria, 1988). En cambio, en ese mismo periodo se beneficiaron de las ayudas para puesta en riego del olivar cerca de 15.000 ha.

\section{DE LA DIVERSIDAD AGRÍCOLA AL MONOCULTIVO}

A finales de los años noventa, momento al que corresponde el segundo grupo de ortofotos utilizadas, ya podían diferenciarse con nitidez tres grandes modelos de dedicación del terrazgo en los poblados elegidos, que perfectamente podía extrapolarse al resto de los núcleos de colonización provinciales con muy ligeras variaciones. El ingreso de España en la entonces Comunidad Económica Europea (CEE) que tuvo lugar el 1 de enero de 1986, resultó determinante en la conformación de dos de ellos, que respondían a la perfección al proceso de especialización productiva del territorio rural, ampliamente extendido en la agricultura comunitaria.

El primero de estos modelos, perceptible en los núcleos de Guadalen y Solana de Torralba, se caracterizaba por el afianzamiento del olivar como cultivo dominante, aunque todavía no había alcanzado el régimen de monocultivo 
ostensible en las grandes y medianas explotaciones de las tierras reservadas de su entorno más inmediato, mucho más proclives a esta dedicación exclusiva del terrazgo. A partir de la incorporación a la CEE, trascendental en la reciente historia de la provincia de Jaén, este árbol mediterráneo, alentado por el suculento sistema de precios y ayudas establecido por la Organización Común de Mercados (OCM) en el sector de las materias grasas vigente en ese momento (Araque, 2010), empezó a expandirse de forma vertiginosa por todo el territorio provincial, sin ningún tipo de excepción, desplazando tanto a los cultivos tradicionales como a los de más reciente implantación, que durante unos años se habían presentado como alternativas viables al olivar y cereal. Aunque la aplicación plena en nuestro país de la beneficiosa OCM no se produjo hasta diez años después de la fecha oficial de ingreso en la CEE, tanto el precio de intervención del aceite, como las ayudas a la producción, crecieron de un modo vertiginoso en ese intervalo de tiempo, y se convirtieron, sin ningún género de dudas, en el principal acicate para la elección del nuevo cultivo.

En ese nuevo contexto económico establecido por la Política Agraria Común (PAC), el terrazgo de los poblados de colonización, y el de las grandes zonas regables en su conjunto, presentaba la ventaja antes mentada de la disponibilidad de agua en abundancia. En el caso del olivar ese recurso resultaba trascendental por cuanto permitía al agricultor incrementar de un modo apreciable los rendimientos de la planta y, en definitiva, beneficiarse en mayor medida de las generosas ayudas a la producción que contemplaba la OCM, cuya cuantía no era desdeñable en modo alguno (Pérez, 2000). Igualmente el regadío permitía atenuar la consabida vecería del olivo, asegurando de este modo la percepción de unas rentas sostenidas en el tiempo, mucho menos fluctuantes que en el olivar de secano, imprescindibles para planificar el futuro de la explotación sin tantos sobresaltos. Por otro lado, el mecanismo de intervención comunitario garantizaba al olivarero la adquisición de todo el aceite producido durante la campaña a un precio equitativo, actuando así como un verdadero colchón de seguridad ante la incertidumbre del mercado.

Bajo estas excelentes perspectivas no es de extrañar que numerosos colonos atisbaran una excelente oportunidad para cambiar de cultivo en ese momento, renunciando con ello para siempre a la práctica de una agricultura alternativa de resultados económicos más parcos e inciertos. Si muchos de ellos no se atrevieron a la transformación de sus explotaciones en esos primeros años de aplicación de la PAC, no fue por otra cosa que por el ya indicado periodo de improductividad de la tierra que llevaba aparejado tal cambio. Al no disponer de otras rentas complementarias, resultaba del todo aventurado adoptar una decisión tan radical.

Por lo demás, no se registraron grandes novedades respecto al resto de la provincia ni en la variedad de árbol seleccionado - picual, en la inmensa mayoría 


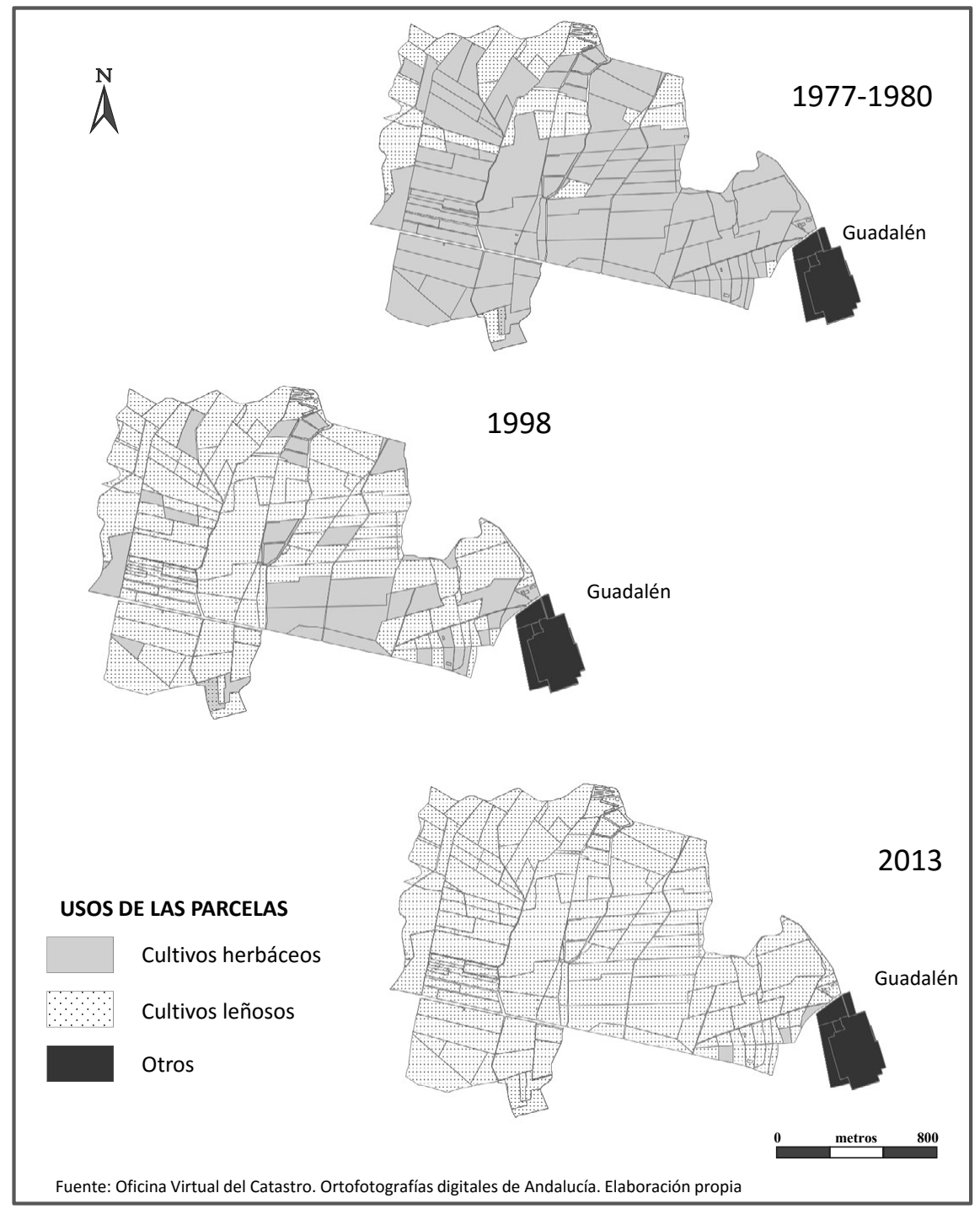

Mapa 1. Evolución de los usos del suelo en Guadalén. 1977-2012.

de los casos-, ni en los marcos de plantación utilizados, que se achicaron mínimamente, pasando de los 12 a los $10 \mathrm{~m}$ o, excepcionalmente, a marcos algo menores y más irregulares. Por lo que atañe al regadío, tampoco se modificó el tradicional sistema de riego a manta mediante el sistema de pozas a pie de árbol, entre otras cosas porque era el único que en esos momentos permitía la infraestructura construida. 


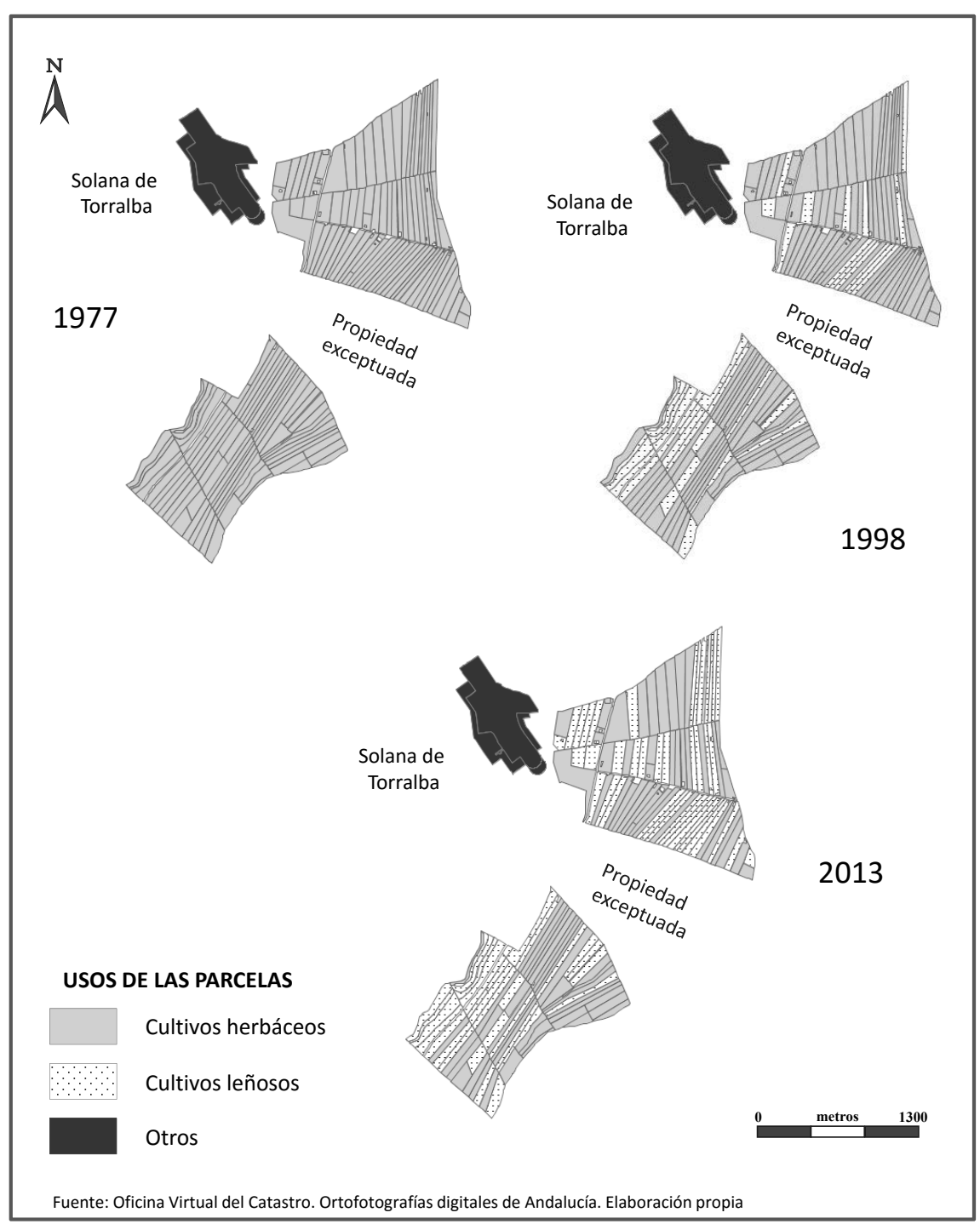

Mapa 2. Evolución de los usos del suelo en Solana de Torralba. 1977-2012.

También tuvo mucho que ver la aplicación de la PAC en la conformación del segundo modelo de monocultivo que se impuso en los poblados de Ampliación de Espelúy y La Quintería. En esta ocasión vinculado al algodón, que sin llegar alcanzar las cotas del olivar en cuanto a apoyo comunitario, tampoco salió mal parado del régimen especial de ayuda -sustitutivo de la OCM, con la que no contaba este sector- al cultivo que se había instaurado 
$\stackrel{N}{\Lambda}$

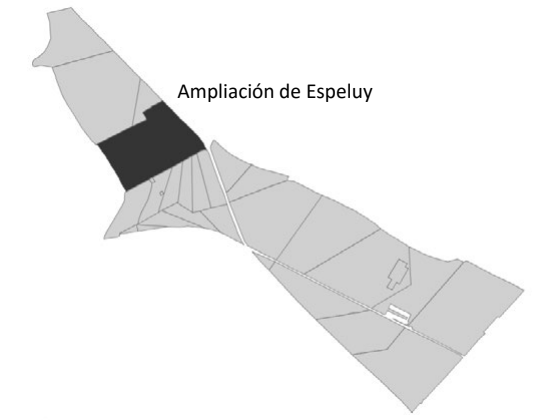

$1977-1980$

A

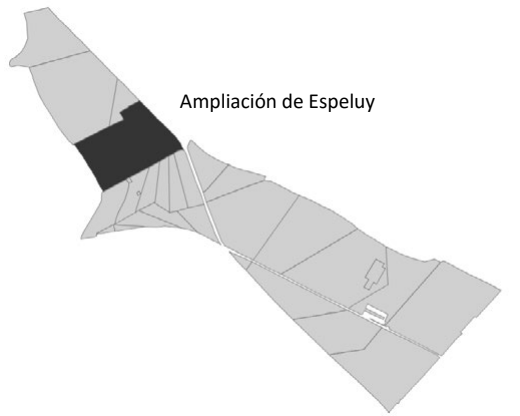

1998

USOS DE LAS PARCELAS

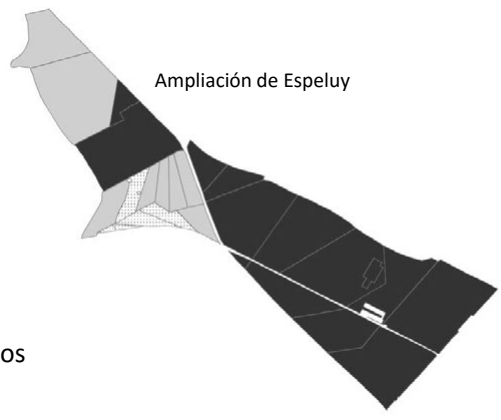

2013

Cultivos herbáceos

Cultivos leñosos

Otros

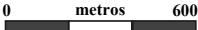

Fuente: Oficina Virtual del Catastro. Ortofotografías digitales de Andalucía. Elaboración propia

Mapa 3. Evolución de los usos del suelo en Ampliación de Espelúy. 1977-2012.

tras el ingreso de Grecia en la CEE en 1981. El apoyo a la producción se materializaba en una ayuda unitaria por cada kilogramo de algodón entregado a la industria desmotadora, que era la encargada de abonarla al agricultor. Todo ello siempre que la fibra mantuviera una cierta calidad y no se sobrepasara la cantidad nacional garantizada individualmente a Grecia y España, en cuyo caso la ayuda disminuía. 


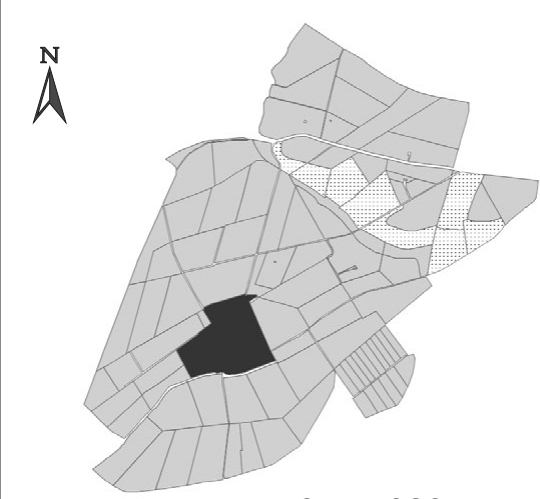

$1977-1980$
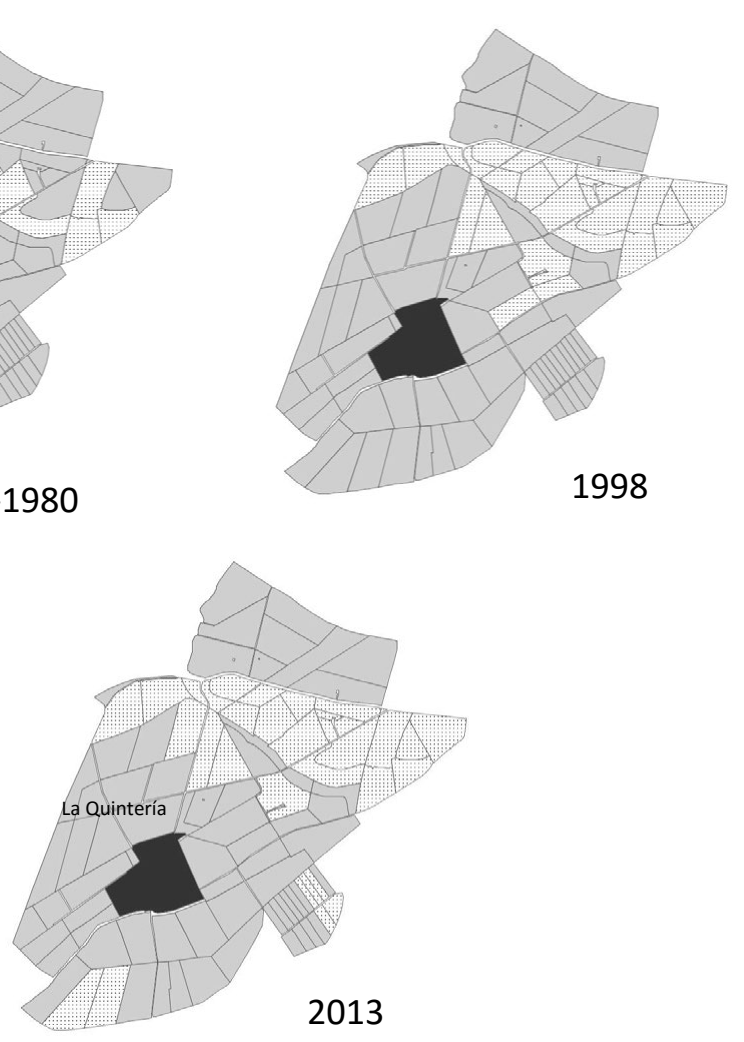

USOS DE LAS PARCELAS

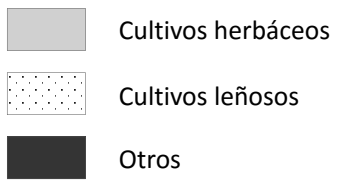

Fuente: Oficina Virtual del Catastro. Ortofotografías digitales de Andalucía. Elaboración propia

Mapa 4. Evolución de los usos del suelo en La Quintería. 1977-2012.

Hay que advertir, no obstante, que a medida que progresaba el monocultivo algodonero en la zona baja del Guadalquivir y del Rumblar, desaparecía a pasos agigantados en las restantes zonas regables. El cierre de las desmotadoras de Mengíbar y Baeza, por un lado, y la apertura de una nueva planta mucho más moderna que las anteriores en la localidad de Marmolejo, influyó en este proceso de concentración del cultivo, no cabe duda, pero no menos importantes fueron 
las continuadas sequías de mediados de los años noventa, que resultaron letales para el algodón e hicieron que muchos de los agricultores menos entrenados en su cultivo, desistieran definitivamente del mismo, implantando en sus explotaciones otros cultivos menos exigentes en agua y, por tanto, más a resguardo de los imprevisibles vaivenes meteorológicos.

La evolución seguida por el terrazgo de Campillo del Río merece un comentario aparte ya que no responde a la generalizada tendencia al monocultivo de las tierras regadas jiennenses. Lo que muestra la ortofoto y corrobora el trabajo de campo efectuado en este poblado de colonización, el mayor de la provincia, tanto por la extensión total de los lotes entregados, como por el número de colonos instalados, es que era el único caso en que no habían decaído los esfuerzos por mantener una horticultura diversificada e innovadora que tanto había perseguido el Plan Jaén. No sólo se introdujeron en las tierras regables nuevos cultivos jamás practicados en la provincia, como el esparrago blanco, pimiento de piquillo, brócoli, etc., sino que se constituyeron las primeras cooperativas de producción para vender sus productos directamente a los grandes exportadores nacionales o a las industrias de transformación, tratando con ello de obtener mejores precios para los asociados. Es más, en algunos casos esas cooperativas consiguieron el arrendamiento de medianos lotes de tierras en otras zonas regables para ampliar el área de cultivo de aquellos productos que ofrecían mayor rentabilidad, como sucedió, por ejemplo, con el esparrago blanco. La venta en fresco de este producto de temporada en los mercados europeos deparaba grandes beneficios a los agricultores, puesto que llegaba al mercado mucho antes que el de cualquier competidor. Era lógico, por tanto, que los productores trataran de expandir por todos los medio este cultivo tan rentable.

\section{LA IMPARABLE EXPANSIÓN DEL OLIVAR}

Las últimas ortofotos empleadas están fechadas en 2013. En ellas se puede observar cómo han evolucionado de forma disímil los grandes modelos descritos. En aquellos poblados en los que tres lustros antes el olivar se erigía en cultivo dominante, la expansión había continuado hasta copar la totalidad de los lotes, familiares y complementarios, como sucedía en Guadalen, o se encontraba muy cerca de alcanzar esa situación, como ocurría en Solana de Torralba. Durante la realización del trabajo de campo, en este último poblado pudimos observar las numerosas parcelas recién plantadas de olivar que aun no habían entrado en producción, lo que significa que en un breve lapso de tiempo se alcanzará la misma situación que en el primero.

La modificación del sistema comunitario de ayuda al aceite de oliva tras la adopción del régimen de pago único a partir de comienzos de 2006, había 
resultado muy beneficiosa para el olivar de regadío puesto que el cálculo de los derechos de cada agricultor se realizó sobre el promedio de producción de las cuatro últimas campañas inmediatamente anteriores a la de promulgación del reglamento de reforma. $Y$ eso, en este caso, significaba una mayor producción y una menor fluctuación del volumen anual de cosecha. En definitiva, una cuantía mayor de los derechos asignados a cada agricultor respecto a los de secano. Por otra parte, no podemos olvidar la creciente revalorización del aceite de oliva en el mercado, erigido ya sin vacilaciones en una grasa de consumo muy saludable para el organismo que se recomendada en todo tipo de dietas. Eso se tradujo de inmediato en un incremento del precio de los caldos en origen, lo que acabó repercutiendo muy favorablemente en la renta percibida por los agricultores.

La expansión del olivar en estos poblados vino acompañada de otros cambios no menos llamativos, que venían a demostrar las grandes esperanzas que se tenían puestas en este cultivo. La más relevante de todas, en línea con lo que se podía apreciar en el resto de la agricultura española (Morales y Hernández, 2010), era, desde luego, la erradicación del sistema de regadío tradicional y la introducción de modernos sistemas de riego localizado cuya principal virtud era su menor y más eficiente consumo de agua. Pero por encima de ese ahorro y de la mayor racionalidad en el uso de un recurso natural escaso en todo el sur peninsular como era el agua, lo que mostraba la transformación del sistema de riego era un cambio histórico espectacular en la mentalidad de los agricultores, no ya sólo de los residentes en los poblados de colonización, sino en toda la provincia. En efecto, por primera vez desde que a mediados del siglo xIx proliferaran las solicitudes para la construcción de canales de riego realizadas por parte de la iniciativa privada, no se habían registrado otros intentos de similar naturaleza. Todas las propuestas e inversiones en regadío efectuadas en la provincia habían tenido como principal protagonista a la iniciativa pública. Ahora volvía a retomarse ese papel promotor, asumiendo personalmente los afectados los elevados costes económicos que implicaba la introducción del riego localizado en sus explotaciones, sin contar apenas con auxilio público. Eso mostraba hasta qué punto podía considerarse excepcional la coyuntura económica que vivía el olivar después del ingreso de España en la UE.

El proceso modernizador se dejó notar también en otros muchos aspectos que no podemos abordar aquí. Sirvan algunos como muestra dos ejemplos. Los nuevos sistemas de riego permitían incrementar la densidad de pies de olivo por unidad de superficie, lo que se hizo en las nuevas plantaciones, muchas de las cuales eran de un solo pie para facilitar la mecanización de la recolección y ahorrar en el principal coste del cultivo, o incrementar el número de árboles en las plantaciones tradicionales, introduciendo nuevos pies en las amplias 
camadas $^{3}$ de los marcos de plantación que habían sido habituales en otras épocas. Así mismo, se plantaron nuevas variedades de olivos distintas a la predominante en la provincia, con finalidades muy distintas: desde el incremento de la producción a la mayor resistencia a las plagas, pasando por la obtención de nuevas clases de aceite. Todas ellas, en cualquier caso, estaban encaminadas a conseguir una mayor eficiencia productiva y una rentabilidad más elevada de las explotaciones.

Los dos modelos en los que se había impuesto el monocultivo algodonero siguieron una evolución completamente diferente. En Ampliación de Espeluy la liquidación de la reforma técnica no llegó de la mano de un cambio interno en el sistema agrario, sino de la reconversión radical en la dedicación del suelo, que de rústico se transformó en urbanizable con el fin de acoger a dos grandes industrias, una de fabricación de traviesas de hormigón para el ferrocarril y otra de reciclaje de neumáticos usados, que empezaron a operar en 2007. La totalidad de los lotes familiares se vieron afectados por esta trascendental modificación, íntimamente asociada a la localización estratégica del poblado junto a la estación ferroviaria de la línea Madrid-Cádiz, paradójicamente cada vez más abandonada y con menos tráfico de viajeros y mercancías. Pero en ello también tuvo mucho que ver la obsesión casi compulsiva por fomentar la industrialización del medio rural jiennense a cualquier precio. Eso llevó al Ayuntamiento de la localidad a promover este cambio de uso, que acabó de un plumazo con medio siglo de historia rural. Aunque no puede considerarse un caso excepcional, pues se repitió a distintas escalas en otros poblados, la urgencia con que se llevó a cabo este proceso en Ampliación de Espelúy y el escaso número de propietarios afectados, impidió plantar cara a esta brusca transformación, que se presentó como la panacea para la creación de empleo industrial en el medio rural, pero que en modo alguno lo ha sido ni lo será.

Únicamente lograron mantenerse a salvo de esta fiebre industrializadora el conjunto de lotes complementarios, en los que el fin de la reforma se manifestó en forma de conversión de casi todos ellos en pequeñas explotaciones de olivar. Entre los pies de olivos aparecen hoy las únicas muestras que quedan de aquella agricultura diversificada que tanto anhelara el INC. Son los diminutos huertos que cada primavera siembran los primitivos colonos del poblado, no tanto con el deseo de autoabastecerse, sino más bien como una forma de entretenimiento que los mantenga activos.

En el cercano poblado de La Quintería, por el contrario, se acentuó durante unos años el monocultivo algodonero, sobre todo después de que la reforma del régimen de ayuda al cultivo, aprobado en 2004 para su aplicación a partir

3. En la jerga olivarera se conoce como camada el pasillo que queda entre dos filas contiguas de árboles. 
de la campaña 2006-2007, desvinculara la ayuda de la producción, esto es, permitía al agricultor cobrar un $65 \%$ de la ayuda comunitaria en concepto de pago único, sembrara o no sembrara algodón, y el $35 \%$ restante en razón de la superficie realmente plantada, aunque no llegara a efectuar la recolección (Arriaza y Gómez-Limón, 2006). En la persistencia del cultivo también incidieron dos hechos de naturaleza muy diferente. Por una parte, la mejora en la

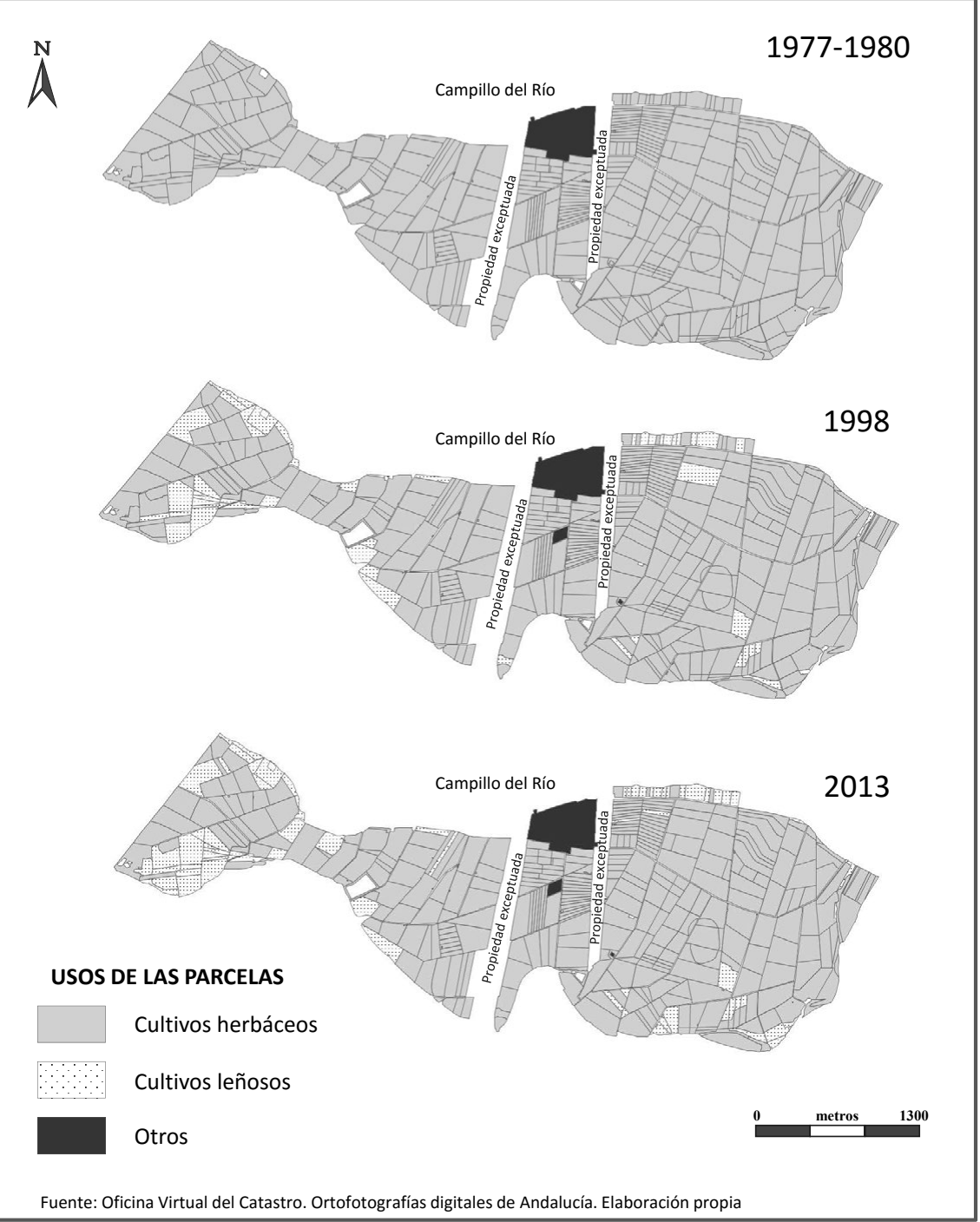

Mapa 5. Evolución de los usos del suelo en Campillo del Río. 1977-2012. 
comercialización del producto a raíz de la creación de almacenes locales de entrega del algodón recolectado, gestionados por los propios agricultores, que les permitió deshacerse de intermediarios y obtener mayores precios al contratar directamente con la industria desmotadora, a la que empezaba a faltarle producto. Por otra parte, el olivar, como cultivo sustitutivo al algodón en estas tierras, presentaba la seria limitación de ser atacado por el hongo verticilium y desarrollar la verticilosis, una enfermedad que podía presentarse en cualquier momento de la fase de crecimiento de la planta, incluso cuando empezaba a dar fruto. Ante esa posibilidad algunos agricultores no se atrevieron a dar el paso de la plantación de olivares sobre las tierras ocupadas anteriormente por el algodón. Otros, en cambio, asumieron el riesgo con muy diferente grado de éxito. La distribución actual de cultivos muestra claramente esas dos estrategias, pero en nuestra opinión, después de la información recaba en el trabajo de campo, la reconversión olivarera tardará en hacerse presente el tiempo que tarde la investigación en encontrar soluciones efectivas para la erradicación de la verticilosis en las nuevas plantaciones de olivar sobre tierras algodoneras.

Finalmente el modelo de horticultura implantado en Campillo del Río, no solo logró consolidarse en estos años, sino que se afianzó plenamente sobre bases más sólidas desde el momento en que a finales de siglo se constituyó en el poblado una cooperativa de transformación industrial de sus variados productos, cuyo radio de acción no se limitaba al terrazgo del poblado sino que se extendía por otros poblados y zonas regables contiguas. En el momento en que se puso en marcha esta empresa daba la impresión de que renacía el espíritu con el que se abordó la reforma técnica de la agricultura, languideciente después de tantos fracasos y falsas expectativas. Con más de medio millar de socios y unas flamantes naves construidas junto al núcleo de colonización, que contaron con una importante inyección de fondos públicos, la cooperativa comenzó a comercializar en fresco una gama de productos hortícolas cada vez más amplia, y a manipular y envasar algunos de ellos, sobresaliendo en ambos casos el espárrago blanco, cuyo mercado interior y exterior se dilataba continuamente. A los productos que comercializaba bajo sus propias marcas, pronto se unieron los que envasaba para otras marcas que dominaban el mercado conservero español, pero que no disponían de materia prima de calidad para seguir ofertándola a sus clientes. Todo ello permitió a la cooperativa la generación anual de más de 4.000 jornales en las distintas temporadas de envasado; una cifra realmente espectacular en una localidad donde apenas se conocía el trabajo por cuenta ajena.

Lo que no había conseguido Sacove ni otras pequeñas industrias similares en los años sesenta, parecía haberlo logrado Horticamp medio siglo después. Pero de pronto todo volvió a convertirse en un cruel espejismo. Apenas una década después de entrar en funcionamiento, la cooperativa quebró y entró en concurso de acreedores, asfixiada en lo económico por la enorme deuda hipotecaria 
contraída, y en lo agronómico por una falta de control a la hora de proceder a la necesaria rotación de las tierras de cultivo, agotadas después de soportar durante años las mismas plantaciones. El mapa más reciente de usos del suelo muestra el incipiente proceso de implantación del olivar en algunos lotes familiares y complementarios. No es más que el preludio de lo que, con toda seguridad, se avecina en los próximos años. No pocos agricultores, completamente decepcionados por los sucesivos fracasos de las experiencias cooperativistas, no se sienten ya con fuerzas para emprender nuevas aventuras empresariales. Y lo que es peor, el relevo generacional, que podría insuflar nuevos aires a la agricultura de regadío, es prácticamente inexistente. Así pues, las probabilidades de que el mar de olivos no acabe cubriendo también a medio plazo el terrazgo de este poblado son muy escasas.

\section{BIBLIOGRAFIA}

ARAQUe, E. (1983): La política de colonización en la provincia de Jaén. Análisis de sus resultados. Instituto de Estudios Giennenses. Jaén.

Araque, E. (2010): El olivar en la provincia de Jaén: evolución reciente y situación actual, en Araque, E. et al.(Coord.): Política regional europea y su incidencia en España. Economía, sociedad y medio ambiente. Asociación Andaluza de Ciencia Regional. Jaén, pp. 271-297.

ARAQUE, E. (2014): Un intento fallido de industrialización agraria a gran escala en la provincia de Jaén, en Cortizo, J. et al.: De la geografía rural al desarrollo local. Homenaje a Antonio Maya Frades. Área de publicaciones de la Universidad de León. León, pp. 109-126.

ARIAS, J. (1951: Una investigación sobre las causas y remedios del paro agrícola y otros problemas de la economía de Jaén. Cuadernos de Información Económico-Social. Jaén. Monográfico.

ArriaZA, M. y Gómez-Limón, J.A. (2006): El futuro del algodón en Andalucía tras la reforma del régimen de apoyo al cultivo, en Revista de Estudios Regionales, n. ${ }^{\circ}$ 77, pp. 13-46.

BosQue, J. (1984): Del INC al IRTDA: análisis de los resultados obtenidos por la política de colonización posterior a la guerra civil, en Agricultura y Sociedad, n. ${ }^{\circ} 32$, pp. 153-191.

DAP (Empresa pública desarrollo agrario y pesquero) (2002): Informe sobre el sector del algodón y la industria transformadora en Andalucía. Consejería de Agricultura y Pesca de la Junta de Andalucía. Sevilla. Original mecanografiado.

Dirección General de La Producción Agraria (1975): Inventario agronómico del olivar. II. Provincia de Jaén. Ministerio de Agricultura. Madrid.

Dirección General de La Producción Agraria (1988): El olivar español. Planes de reestructuración y reconversión. Ministerio de Agricultura. Madrid.

GALLEGo, V. J. (2012): Una oportunidad perdida para el desarrollo de la provincia de Jaén en las décadas centrales del siglo XX. Antecedentes, desarrollo y resultados del Plan Jaén de 1953. Servicio de Publicaciones de la Universidad de Jaén. Jaén. 
JimÉNEZ, A. (1997): La Organización Común de Mercado del aceite de oliva: instrumentos de regulación, en Parras Rosa, M. (Coord.): La reforma de la OCM y el futuro del olivar. Universidad de Jaén. Jaén, pp. 297-330.

López, A. (1980): ¿Qué pasa con el olivar? Publicaciones del Instituto de Desarrollo Regional de la Universidad de Granada. Granada.

Martín, M. (1996): Enira y el Plan Nacional de aprovechamientos de residuos agrícolas de 1952: historia de un fracaso, en Revista de Historia Industrial, n. ${ }^{\circ}$ 9, pp. 117-152.

Morales, A. (2003): Eficiencia de los regadíos españoles, en Cuadernos de Geografía, nos. 73-74, pp. 323-342.

Morales, A. y HernándeZ, M. (2010): Mutaciones de los usos del agua en la agricultura española durante la primera década del siglo XXI, en Investigaciones geográficas, n. ${ }^{\circ}$ 51, pp. $27-51$.

PÉREZ, P. P. (2000): La demanda de aceite de oliva en España y la política agraria de la Unión Europea. Publicaciones e la Escuela de Técnica Empresarial Agraria. Córdoba.

Rodríguez, A. y Ruiz, P. (1996): El sistema agroindustrial del algodón en España. Publicaciones del Ministerio de Agricultura, Pesca y Alimentación. Madrid.

Sumpsi, J. M. (1980): Política agraria y racionalidad económica en las explotaciones capitalistas: el caso del algodón de secano en las campiñas de Andalucía, en Agricultura y Sociedad, n. ${ }^{\circ}$ 14, pp. 79-126.

TIó, C. (1982): La política de aceites comestibles en la España del siglo XX. Publicaciones del Ministerio de Agricultura, Pesca y Alimentación. Madrid.

Velasco, A. (1976): Consideraciones sobre las condiciones económicas del algodón en Andalucía, en Revisa de Estudios Agrosociales, n. ${ }^{\circ}$ 95, pp. 241-254. 